\title{
Intolerância Glicêmica e o Prognóstico Perinatal em Gestantes Utilizando Anti-Retrovirais
}

Carbohydrate Intolerance and the Perinatal Prognosis in Pregnant Women Making Use of Antiretroviral Drugs

Geraldo Duarte, Patrícia El Beitune, Ernesto Antonio Figueiró-Filho, Silvana Maria Quintana, Alessandra Cristina Marcolin

Objetivos: estudar o efeito das drogas anti-retrovirais sobre o metabolismo glicêmico em gestantes portadoras do HIV-1 e a ação dessas medicações sobre o prognóstico perinatal.

Métodos: estudo prospectivo realizado em 57 gestantes divididas em três grupos: Grupo AZT, utilizando zidovudina ( $n=20$ ); Grupo TT, utilizando zidovudina+lamivudina+nelfinavir $(n=25)$, e Grupo Controle, gestantes normais $(n=12)$. Obteve-se a área sob a curva (ASC) das glicemias após teste oral de tolerância à glicose com $75 \mathrm{~g}$ de glicose em quatro oportunidades durante a gravidez $\left(1^{\circ}=14-20\right.$ semanas; $2^{\circ}=21-26$ semanas; $3^{\circ}=27-32$ semanas e $4^{\circ}=33-38$ semanas). O prognóstico perinatal levou em consideração as taxas de prematuridade, restrição de crescimento intra-útero (RCIU), baixo peso ao nascer, mortalidade perinatal e transmissão vertical do HIV-1. Os dados foram analisados utilizando-se os testes não paramétricos do $\chi^{2}$, teste de Friedman e teste de KruskalWallis.

Resultados: os valores da mediana da ASC foi de $11.685 \mathrm{mg} / \mathrm{dL}$ para o Grupo Controle, $13.477 \mathrm{mg} / \mathrm{dl}$ para o Grupo AZT e $13.650 \mathrm{mg} / \mathrm{dL}$ para o Grupo TT (p=0,049). Não se observou efeito deletério dos anti-retrovirais sobre as taxas de prematuridade, baixo peso ao nascer, RCIU e indices de Apgar. Não houve nenhum caso de transmissão vertical do $H I V-1$.

Conclusões: verificou-se o desenvolvimento de intolerância glicêmica em gestantes que utilizaram tratamento triplice, não sendo observado naquelas que utilizaram apenas AZT. Não houve efeitos deletérios dos anti-retrovirais sobre o prognóstico perinatal.

PALAVRAS-CHAVE: Anti-retrovirais. Infecções na gravidez. Metabolismo glicídico. Prognóstico perinatal. Transmissão vertical.

Publicado como trabalho completo na Rev Bras Ginecol Obstet 2003; 25: 465-71. 


\section{Pesquisa da Prevalência do Papilomavirus Humano (HPV) em Amostras de Tecido Endometrial Normal e com Carcinoma pela Técnica de PCR}

Study on the Prevalence of Human Papillomavirus (HPV) in Samples of Endometrial Tissue, both Normal and with Carcinoma, using the PCR Technique

Edison Natal Fedrizzi, Newton Sérgio de Carvalho, Luisa Lina Villa, Irene Vieira de Souza, Ana Paula Martins Sebastião

Objetivo: comparar a prevalência da presença do DNA do HPV pela técnica de PCR em amostras de tecido endometrial normal e com carcinoma endometrial de mulheres submetidas a tratamento cirúrgico (histerectomia) por carcinoma endometrial e doença benigna e a sua correlação com a idade, tabagismo, diferenciação escamosa e grau de diferenciação tumoral, tipo viral mais frequente e trofismo endometrial nas mulheres sem carcinoma.

Métodos: trata-se de estudo observacional do tipo caso-controle em que foram avaliadas 100 mulheres (50 com endométrio normal e $50 \mathrm{com}$ carcinoma endometrial) quanto à presença do DNA do HPV em amostra tecidual conservada em blocos de parafina, pelo método de PCR.

Resultados: o risco relativo estimado da presença do HPV foi o mesmo nas mulheres com e sem carcinoma endometrial. A presença do HPV não esteve correlacionada com a idade das mulheres, tabagismo, trofismo endometrial, diferenciação escamosa e grau de diferenciação tumoral. O HPV 16 e 18 (5 dos casos com tipo 16 e 4 com o tipo 18) foram os virus mais freqüentemente encontrados.

Conclusão: o HPV está presente no tecido endometrial de mulheres com carcinoma endometrial na mesma proporção que nas com tecido endometrial normal, não demonstrando a possivel associação deste vírus no desenvolvimento do carcinoma endometrial.

PALAVRAS-CHAVE: Papilomavirus humano. HPV. Oncogênese. Carcinoma endometrial. 